\title{
EDITORIAL
}

\section{Diez años después: La fluidez de la revista MCT}

Rubén A. Ananías

Director-Editor

Cuando en junio del año 2001, nos encomendaron la misión de dirigir la revista Maderas. Ciencia y tecnología (MCT), comenzamos a imaginar una revista de carácter científico que contribuyera a mostrar a la sociedad una visión original del cultivo de las ciencias de la madera.

Desde el primer numero impreso en mayo de 1998, MCT-v1n1-1998, conteniendo seis artículos y dos notas técnicas, hasta el numero del décimo aniversario, que presentamos en esta ocasión en versión impresa y acceso abierto en texto completo en internet, MCT-v10n3-2008, conteniendo ocho artículos, la revista ha fluido como lo imagináramos inicialmente, siendo reconocida por la calidad de sus contenidos y progresivo prestigio con responsabilidad social científica.

La fluidez científica de la revista MCT puede ser descrita en términos cualitativos y cuantitativos, en el primer caso se creó un comité científico internacional para fortalecer el proceso de revisión por pares (peer review) que cautelara la calidad de nivel mundial de sus contenidos y se concentraron esfuerzos para otorgar visibilidad internacional a la revista MCT, mediante la indización en bases de datos pertinentes, favoreciendo con ello el prestigio cualitativo de la revista MCT, la cuantificación del prestigio alcanzado por la revista MCT esta actualmente siendo determinado por los indicadores bibliométricos, tales como, el factor de impacto (JCR) desarrollado por las bases de datos del ISI-Web of Science, el ranking de revistas científicas de las bases de datos Scopus (SJR) y el índice de impacto de Scielo.

El fortalecimiento del proceso de revisión por pares (peer review) se ha materializado a través de la internacionalización del comité científico, incorporándose a éste, una red de destacados investigadores en ciencias de la madera, tales como Anthony HASLETT (Ensis, Nueva Zelanda, 2001), Roger HERNANDEZ (U. Laval, Canadá, 2001), Rodolfo NEUMANN (U. Concepción, Chile, 2001), Antonio PIZZI (Enstib, Francia, 2001), Thomas MANNES (UBC, Canadá, 2001), Shusheng PANG (U. Canterbury, Nueva Zelanda, 2002), Alain CLOUTIER (U. Laval, Canadá, 2005), Roger KEEY (WRC, Nueva Zelanda, 2005), Patrick PERRE (Engref, Francia, 2005), Luis VALENZUELA (U. Concepción, Chile, 2005), Andrés WEINTRAUB (U. Chile, Chile, 2005), Howard ROSEN (USDA, USA, 2006) y Frank BEALL (UCLA, USA, 2007), este comité científico junto a muchos otros distinguidos investigadores que anónimamente han actuado como examinadores de manuscritos, evidentemente han fortalecido el proceso de revisión por pares (peer review) y el aporte científico a las contribuciones sometidas a la revista MCT. La originalidad de las contribuciones de los autores y el aporte científico de los examinadores han ciertamente favorecido la calidad de los contenidos de la revista MCT. En cifras del año 2007, la participación de los examinadores internacionales fue de más del 63\% del total de evaluadores de ese año. Y se aprobaron un $68 \%$ del total de manuscritos sometidos como probable publicación a la revista MCT.

Respecto de la visibilidad mundial de la revista MCT, destacan entre otras indizaciones, CAB Abstracts (Forest Products Abstracts, Forestry Abstracts, Agricultural Engineering Abstracts) el año 2003, Scielo y Redalyc el año 2005, Scopus (Scimago Journal Rank), Chemical Abstracts (Scifinder Scholar) y Cambridge Scientific Abstracts (Technological Research Database, Engineering Research Database) el año 2007 e ISI-Web of Science (Science Citation Index Expanded, Journal Citation Report/Science Edition, Materials Science Citation Index) el año 2008. En este ámbito la indización en la biblioteca 
de revistas científicas en línea Scielo el año 2005, fue un hito muy importante que nos abrió mayores opciones para indizar la revista en otras bases de datos internacionales tales como el acceso al selectivo grupo de revistas de Scopus el año 2007 y del ISI-Web of Science el año 2008, este último ha permitido que la revista MCT haya fluido desde la denominada corriente periférica a una publicación de corriente principal, reconociéndose con ello el prestigio cualitativo de la revista MCT.

En cuanto al prestigio científico cuantificable de la revista MCT, podemos indicar que en el ranking de revistas científicas de Scopus (SJR), la revista MCT obtuvo el año 2007 un SJR=0.046, con lo cual se ubicó entre las mejores 50 revistas científicas del mundo forestal y en el octavo mejor lugar entre todas las revistas científicas chilenas. El factor de impacto publicado por el ISI-Web of Science del año 2007, para las ocho revistas internacionales de ciencias de la madera fue entre 0.148 y 0.811 , la revista MCT no aparece citada, debido a su reciente incorporación al ISI, no obstante, de acuerdo a nuestros cálculos, la revista MCT obtendría un índice de citas para el año 2007 de 0.194, esto es, comparable al factor de impacto de estas prestigiosas revistas internacionales e igualmente comparable al factor de impacto publicado para las diez revistas chilenas de todas las áreas que varió entre 0.155 a 1.057.

Por otra parte la contribución a la sociedad del trabajo científico desarrollado por la revista MCT, ha sido con la firme convicción de mantener el acceso abierto, en texto completo, gratuito y sin ningún tipo de embargo, de todos los manuscritos publicados en la revista MCT. En tal sentido la responsabilidad social científica, ha sido un compromiso permanente, particularmente a partir del año 2005, cuando la revista fuera seleccionada por la biblioteca de revistas científicas en línea Scielo, quedando disponible en texto completo y acceso abierto en dicha biblioteca en internet, al mismo tiempo fue incorporada en texto completo al Directorio de revistas con acceso abierto en internet (DOAJ), seleccionada en la red latinoamericana de revistas científicas (Redalyc) durante el año 2005, agregada a la base de datos Periódica el año 2006 y puesta en texto completo y acceso libre en internet de los volúmenes pertinentes a los años 2001-2004 en la biblioteca de revistas científicas en línea (Scielo).

Last but not least, nos sentimos orgullosos de lo que hemos cultivado a través de la revista Maderas. Ciencia y tecnología, celebramos 10 años de fluidez, en base a imaginación y rigor científico, con crecientes estándares de calidad y sostenida responsabilidad social científica, y estamos optimistas que en el futuro continuaremos convocando a los científicos del mundo de las ciencias de la madera a comunicar sus hallazgos en nuestra revista. 